\title{
A Young Adult Patient with Nonalcoholic Steatohepatitis Developed Severe Gastroesophageal Varices Associated with Severe Obesity and Diabetes Mellitus
}

\author{
Yuichi Honma Kazuhiro Sumida Noriyoshi Ogino Masashi Kusanaga \\ Sota Minami Shinsuke Kumei Hidehiko Matsuoka \\ Tatsuyuki Watanabe Masaaki Hiura Shintaro Abe Michihiko Shibata \\ Masaru Harada \\ Third Department of Internal Medicine, School of Medicine, University of Occupational \\ and Environmental Health, Kitakyushu, Japan
}

\section{Keywords}

Nonalcoholic steatohepatitis · Young patient · Insulin resistance · Obesity · Gastroesophageal varices

\begin{abstract}
Obesity is a major contributor to insulin resistance and nonalcoholic fatty liver disease, which is the most common cause of chronic liver diseases. Nonalcoholic steatohepatitis (NASH) can progress to liver cirrhosis and end-stage liver diseases. Some cases already show severe liver fibrosis at the time of diagnosis. We present the case of a 44-year-old male with overt obesity who was admitted with hematemesis due to the rupture of gastric varices. We diagnosed him with NASH with severe liver fibrosis. This case shows that we should be concerned about the progression of liver fibrosis due to NASH associated with severe obesity even in young patients.




\section{Case Reports in Gastroenterology}

Case Rep Gastroenterol 2018:12:487-496

DOI: $10.1159 / 000492423$

(c) 2018 The Author(s). Published by S. Karger AG, Basel www.karger.com/crg

Honma et al.: A Young Adult Patient with Nonalcoholic Steatohepatitis Developed

Severe Gastroesophageal Varices Associated with Severe Obesity and Diabetes Mellitus

\section{Introduction}

As obesity and metabolic syndrome have become more prevalent, nonalcoholic fatty liver disease (NAFLD) has emerged as a common cause of chronic liver diseases. NAFLD includes both NAFL and nonalcoholic steatohepatitis (NASH), which can progress through the stages of liver fibrosis to cirrhosis and can be complicated by liver failure and hepatocellular carcinoma (HCC) [1]. NAFLD is characterized by fat accumulation in the liver and is considered the hepatic manifestation of metabolic syndrome. The diagnosis of NASH is based on histological findings of liver biopsy specimens and is characterized by steatosis, hepatocyte ballooning, inflammatory cell infiltration, Mallory-Denk body (MDB), and fibrosis [2]. Although the pathogenesis of NASH is not completely understood, the "multiple-hit" hypothesis largely explains the pathogenesis and progression of NAFLD [3]. Insulin resistance, which is usually influenced by a sedentary lifestyle, high-caloric diets, genetic susceptibility, and epigenetics, has been reported to play an important role in the development of NASH. Liver steatosis is frequently demonstrated in patients with obesity and type 2 diabetes mellitus (T2DM). Additionally, the severity of pathological findings of NASH, such as lobular inflammation and fibrosis, has been shown to correlate with the extent of insulin resistance [4]. NAFLD has been increasing in younger patients due to the increased prevalence of obesity in children and young adults [5]. Complications of cirrhotic NASH, including bleeding of gastroesophageal varices, liver failure, and HCC, are lethal in some cases. Thus, it is important to differentiate NASH from NAFL before progression to severe liver fibrosis. Although liver biopsy remains the gold standard for the diagnosis of NASH and the evaluation of liver fibrosis, liver biopsy is invasive with a risk of complications. Thus, early and accurate diagnosis of cirrhotic NASH is occasionally difficult, especially in younger patients without primary disease or a related medical history.

Here, we present a young adult patient with severe obesity whose first manifestation of NASH was hematemesis due to the rupture of gastric varices.

\section{Case Presentation}

A 44-year-old male was emergently admitted to our hospital because of hematemesis due to the rupture of gastroesophageal varices. Prior to admission, he had no remarkable medical history. There was no family history of liver diseases. He was not a habitual drinker and did not take other drugs. Two years before admission, his height was $172.2 \mathrm{~cm}$, his body weight was $120.1 \mathrm{~kg}$, and his BMI was 40.5. On admission, his body weight was $116.7 \mathrm{~kg}$ and his BMI was 39.4. Physical examination demonstrated mild anemia in the palpebral conjunctiva and hepatosplenomegaly in the abdomen. Neurological findings were not remarkable. Laboratory data are shown in Table 1 . White blood cell count was increased $(15,100 / \mu \mathrm{L})$, and platelet count was within normal limits $\left(18.3 \times 10^{4} / \mu \mathrm{L}\right)$, while hemoglobin was $7.0 \mathrm{~g} / \mathrm{dL}$ due to bleeding. Biochemical examination showed serum total bilirubin $0.8 \mathrm{mg} / \mathrm{dL}$, albumin $2.9 \mathrm{~g} / \mathrm{dL}$, aspartate aminotransferase (AST) $19 \mathrm{U} / \mathrm{L}$, alanine aminotransferase (ALT) $18 \mathrm{U} / \mathrm{L}$, alkaline phosphatase $135 \mathrm{U} / \mathrm{L}$, and gamma-glutamic transpeptidase $65 \mathrm{U} / \mathrm{L}$, respectively. C-reactive protein was slightly elevated $(1.33 \mathrm{mg} / \mathrm{dL})$. Hyaluronic acid $(187 \mathrm{ng} / \mathrm{mL})$, type 4 collagen $(248$ $\mathrm{ng} / \mathrm{mL}$ ), and Mac2-binding protein (2.71 COI) were increased. Aspartate aminotransferase to platelet ratio index (APRI) [6] and fibrosis-4 (FIB4) index [7] were not elevated (APRI $=0.346$ 


\section{Case Reports in Gastroenterology}

Case Rep Gastroenterol 2018:12:487-496

DOI: $10.1159 / 000492423$

(c) 2018 The Author(s). Published by S. Karger AG, Base www.karger.com/crg

Honma et al.: A Young Adult Patient with Nonalcoholic Steatohepatitis Developed

Severe Gastroesophageal Varices Associated with Severe Obesity and Diabetes Mellitus

and FIB4 index $=1.08$, respectively). APRI and FIB4 were calculated according to the following formula; APRI = AST level (IU/L) / upper limit of normal AST $\times 100 /$ platelet count $\left(10^{9} / \mathrm{L}\right)$, and FIB4 $=$ age $($ year $) \times$ AST $($ IU $/ \mathrm{L}) /$ platelet count $\left.\left(10^{9} / \mathrm{L}\right) \times[\text { ALT }(\mathrm{U} / \mathrm{L})]^{1 / 2}\right\}$. Serum ferritin and ceruloplasmin were within normal limits. Hepatitis B surface antigen, hepatitis B virus core antibody, and hepatitis $\mathrm{C}$ virus antibody were all negative. Antinuclear antibody was elevated $(\times 160)$, whereas antimitochondrial antibody and antiglutamic acid decarboxylase antibody were negative. Immunoglobulins, including IgG, IgM, and IgA, were within normal limits. Coagulation tests revealed a decrease in the percentage of prothrombin time (53.6\%). Hemoglobin A1c was 8.1\%, glycoalbumin was $16.7 \%$, fasting plasma glucose (FPG) was $298 \mathrm{mg} / \mathrm{dL}$, immunoreactive insulin (IRI) was $14.5 \mu \mathrm{U} / \mathrm{mL}$, and homeostatic model of assessment of insulin resistance (HOMA-IR) was 10.7. The HOMA-IR was calculated based on fasting values of plasma glucose and insulin according to the HOMA model formula: HOMA-IR $=\operatorname{IRI}(\mu \mathrm{U} / \mathrm{mL}) \times$ FPG (mg/dL) / 405. Quantitative insulin sensitivity check index (QUICKI) was 0.28. The QUICKI was a novel and accurate method for determining insulin resistance; QUICKI = 1 / (log fasting IRI $[\mu \mathrm{U} / \mathrm{mL}]+\log$ FPG [mg/dL]) [8]. Abdominal ultrasonography examination showed brightness, mild hepatorenal echo contrast, surface irregularity, dullness of the edge of the liver, and splenomegaly (Fig. 1a-c). Contrast-enhanced computed tomography (CT) demonstrated enlargement of the left hepatic lobe and splenomegaly, which corresponded to liver cirrhosis (Fig. 1d). Active contrast material extravasation was also seen, which represented active bleeding from gastroesophageal varices (Fig. 1e, f). Esophagogastroduodenoscopy (EGD) showed gastroesophageal varices (Fig. 1g, h). White plug, which seemed to be the bleeding lesion, was also seen in gastric varices (Fig. 1i). The varices were treated by endoscopic injection sclerotherapy and endoscopic variceal ligation. The histological findings of liver biopsy were mild steatosis, mild chronic inflammatory cell infiltrate, and severe fibrosis in the expanded portal areas with bridging fibrosis and spotty or focal necrosis (Fig. 2a-d). Vacuolation of the nucleus (Fig. 2e) and MDBs (Fig. 2f) were also seen. Immunostaining using antip62/SQSTM1 antibody (Medical and Biological Laboratories, Nagoya, Japan) demonstrated MDBs, which were irregularly shaped cytoplasmic inclusions (Fig. 3c, d) typically located in proximity to the nucleus (Fig. 3 arrows). Based on these findings, the patient was diagnosed with portal hypertension and liver cirrhosis due to NASH. He was also diagnosed, for the first time, with T2DM based on the following findings: FPG exceeding $126 \mathrm{mg} / \mathrm{dL}$, random glucose level over $200 \mathrm{mg} / \mathrm{dL}$, and hemoglobin A1c over 6.5\%. Because hyperglycemia persisted after admission, we started insulin therapy. After starting insulin treatment, hyperglycemia immediately improved. Subsequently, we started the administration of tofogliflozin, a sodium glucose cotransporter 2 (SGLT2) inhibitor.

\section{Discussion}

NAFLD is considered the hepatic manifestation of metabolic syndrome, which is associated with obesity, insulin resistance, T2DM, hypertension and dyslipidemia. NAFLD includes NASH, which can progress the liver fibrosis to cirrhosis and can be complicated by endstage liver diseases, including HCC [1]. The pathogenesis of NASH has been reported to be closely associated with insulin resistance, which is related to metabolic syndrome, oxidative stress, endoplasmic reticulum stress, adipocytokines, and endotoxins [4]. Insulin resistance 


\section{Case Reports in Gastroenterology}

Case Rep Gastroenterol 2018:12:487-496

DOI: $10.1159 / 000492423$

(c) 2018 The Author(s). Published by S. Karger AG, Basel www.karger.com/crg

Honma et al: A Young Adult Patient with Nonalcoholic Steatohepatitis Developed

Severe Gastroesophageal Varices Associated with Severe Obesity and Diabetes Mellitus

increases peroxisomal oxidation and subsequently amplifies reactive oxygen species and lipid peroxidation in hepatocytes. This activates Kupffer cells and hepatic stellate cells, which cause the synthesis of tumor necrosis factor $\alpha$ and other proinflammatory and fibrogenic cytokines [9]. However, the detailed interactions between these mechanisms remain unclear.

The diagnosis of NASH is first established by the exclusion of other etiologies of liver diseases. Liver biopsy remains the gold standard for the diagnosis of NASH. The pathological classification of NAFLD using Matteoni's classification was simple steatosis (type 1) to NASH with Mallory's hyaline (now designated as MDB) or fibrosis with portal inflammation (type 4) [2]. The pathological findings of the present case showed severe fibrosis, portal inflammation, and MDBs (Fig. 2), which were classified as type 4. The NAFLD activity score of this patient was 5 (steatosis 1, lobular inflammation 2, and ballooning 2). We also performed immunohistochemical analyses of MDBs using anti-p62/SQSTM1 antibody. Compared with hematoxylin and eosin staining (Fig. 3a, b), MDBs could be detected more clearly in p62 immunostaining (Fig. 3c, d). We previously reported that the p62 immunostaining analysis was very useful for detecting MDBs, especially when MDBs were very small and/or lipid droplets were present in hepatocytes [10]. Although antinuclear antibody was positive, the serum concentration of IgG was low. Thus, we diagnosed the patient with liver cirrhosis due to NASH. On the other hand, steatosis of the liver biopsy specimen was mild. We considered the mild steatosis corresponded with the histological findings of "burned-out NASH", the progressed-stage of NASH.

A previous study demonstrated that a high BMI $(\geq 28)$ was a significant and independent factor of septal fibrosis in the liver [11]. The World Health Organization (WHO) has defined BMI 25.0-29.9 as preobese, BMI 30.0-34.9 as obese class I, BMI 35.0-39.9 as obese class II, and BMI > 40.0 as obese class III. In Asian populations, a high risk of T2DM and cardiovascular disease is substantial at a lower BMI than the present WHO cutoff for overweight (BMI 25.0) [12]. Our patient had long-term overt obesity for at least 2 years, defined as WHO class II-III. The parameters of insulin resistance, HOMA-IR, and QUICKI were quite high in this patient at admission to our hospital. In addition, both serum IRI and urinary C-peptide excretion were elevated. These results suggest that hyperinsulinemia due to severe insulin resistance had been present. Because hyperinsulinemia has been shown to stimulate tissue growth factor expression [13], the progression of liver fibrosis in the present patient was based on severe obesity and insulin resistance. We started the administration of SGLT2 inhibitor, which acts to improve hyperglycemia by promoting urinary glucose excretion independently of secretion or action of insulin, for T2DM. Some reports showed that SGLT2 inhibitor improved the pathogenesis of NASH by reducing insulin resistance, anti-inflammatory, and antifibrotic effect in mice [14]. Further observation will be needed for the assessment of the efficacy of SGLT2 inhibitor on NASH in this patient.

The frequency of the development of liver cirrhosis in NASH was reported to be about $0.7-3.6 \%$ per year [15]. Because the majority of NAFLD patients seem to be asymptomatic even in the case of liver cirrhosis, aside from severe obesity, high insulin resistance and longterm DM may have caused the progression of liver fibrosis in this patient. Liver fibrosis markers, including hyaluronic acid, type 4 collagen, and Mac2-binding protein, were considered useful fibrosis markers of NASH. The elevation of liver fibrosis markers in this patient also suggested the progression of liver fibrosis. However, APRI and FIB4 index, the other noninvasive liver fibrosis assessment methods were within the normal range for both aminotransferase levels and platelet count. We should be careful when evaluating the progression of liver 
fibrosis in NASH, especially in patients without an increase of aminotransferase levels and/or decrease of platelet count. Bleeding of gastroesophageal varices is a well-established complication of end-stage liver disease, and its mortality rate is very high. Although the real rate of gastroesophageal variceal bleeding as the first manifestation in NASH is unclear, this complication can be lethal, especially when there is underlying long-term obesity and poorly controlled hyperglycemia, as in the present case. Thus, we should carefully assess the progression of liver fibrosis and portal hypertension of severely obese patients with NAFLD, especially those with normal aminotransferase levels and platelet counts. Furthermore, NAFLD has been demonstrated to affect the risk of developing T2DM and other metabolic syndrome-related life-threatening complications, such as cardiovascular diseases.

In conclusion, we should be aware of the possibility of NASH with liver fibrosis and carefully monitor its complications in patients with long-term severe obesity. We should also perform regular follow-up for fibrosis markers, ultrasonography, and/or EGD in these patients.

\section{Statement of Ethics}

The authors have no ethical conflicts to disclose.

\section{Disclosure Statement}

The authors declare that they have no conflicts of interest.

\section{References}

1 Angulo P. Nonalcoholic fatty liver disease. N Engl J Med. 2002 Apr;346(16):1221-31.

2 Matteoni CA, Younossi ZM, Gramlich T, Boparai N, Liu YC, McCullough AJ. Nonalcoholic fatty liver disease: a spectrum of clinical and pathological severity. Gastroenterology. 1999 Jun;116(6):1413-9.

3 Tilg H, Moschen AR. Evolution of inflammation in nonalcoholic fatty liver disease: the multiple parallel hits hypothesis. Hepatology. 2010 Nov;52(5):1836-46.

4 Dixon JB, Bhathal PS, O'Brien PE. Nonalcoholic fatty liver disease: predictors of nonalcoholic steatohepatitis and liver fibrosis in the severely obese. Gastroenterology. 2001 Jul;121(1):91-100.

5 Doycheva I, Watt KD, Alkhouri N. Nonalcoholic fatty liver disease in adolescents and young adults: the next frontier in the epidemic. Hepatology. 2017 Jun;65(6):2100-9.

6 Wai CT, Greenson JK, Fontana RJ, Kalbfleisch JD, Marrero JA, Conjeevaram HS, et al. A simple noninvasive index can predict both significant fibrosis and cirrhosis in patients with chronic hepatitis C. Hepatology. 2003 Aug;38(2):518-26.

7 Sterling RK, Lissen E, Clumeck N, Sola R, Correa MC, Montaner J, et al.; APRICOT Clinical Investigators. Development of a simple noninvasive index to predict significant fibrosis in patients with HIV/HCV coinfection. Hepatology. 2006 Jun;43(6):1317-25.

8 Katz A, Nambi SS, Mather K, Baron AD, Follmann DA, Sullivan G, et al. Quantitative insulin sensitivity check index: a simple, accurate method for assessing insulin sensitivity in humans. J Clin Endocrinol Metab. 2000 Jul;85(7):2402-10.

9 Leclercq IA, Da Silva Morais A, Schroyen B, Van Hul N, Geerts A. Insulin resistance in hepatocytes and sinusoidal liver cells: mechanisms and consequences. J Hepatol. 2007 Jul;47(1):142-56.

10 Hiura M, Honma Y, Miyagawa K, Oe S, Shimajiri S, Mihara H, et al. Alleviation mechanisms against hepatocyte oxidative stress in patients with chronic hepatic disorders. Hepatol Res. 2015 Nov;45(11):1124-35. 
11 Ratziu V, Giral P, Charlotte F, Bruckert E, Thibault V, Theodorou I, et al. Liver fibrosis in overweight patients. Gastroenterology. 2000 Jun;118(6):1117-23.

12 Expert Consultation WH; WHO Expert Consultation. Appropriate body-mass index for Asian populations and its implications for policy and intervention strategies. Lancet. 2004 Jan;363(9403):157-63.

13 Paradis V, Perlemuter G, Bonvoust F, Dargere D, Parfait B, Vidaud M, et al. High glucose and hyperinsulinemia stimulate connective tissue growth factor expression: a potential mechanism involved in progression to fibrosis in nonalcoholic steatohepatitis. Hepatology. 2001 Oct;34(4 Pt 1):738-44.

14 Jojima T, Tomotsune T, Iijima T, Akimoto K, Suzuki K, Aso Y. Empagliflozin (an SGLT2 inhibitor), alone or in combination with linagliptin (a DPP-4 inhibitor), prevents steatohepatitis in a novel mouse model of nonalcoholic steatohepatitis and diabetes. Diabetol Metab Syndr. 2016 Jul;8(1):45.

15 Hashimoto E, Tokushige K. Prevalence, gender, ethnic variations, and prognosis of NASH. J Gastroenterol. 2011 Jan;46(S1 Suppl 1):63-9. 


\section{Case Reports in Gastroenterology}
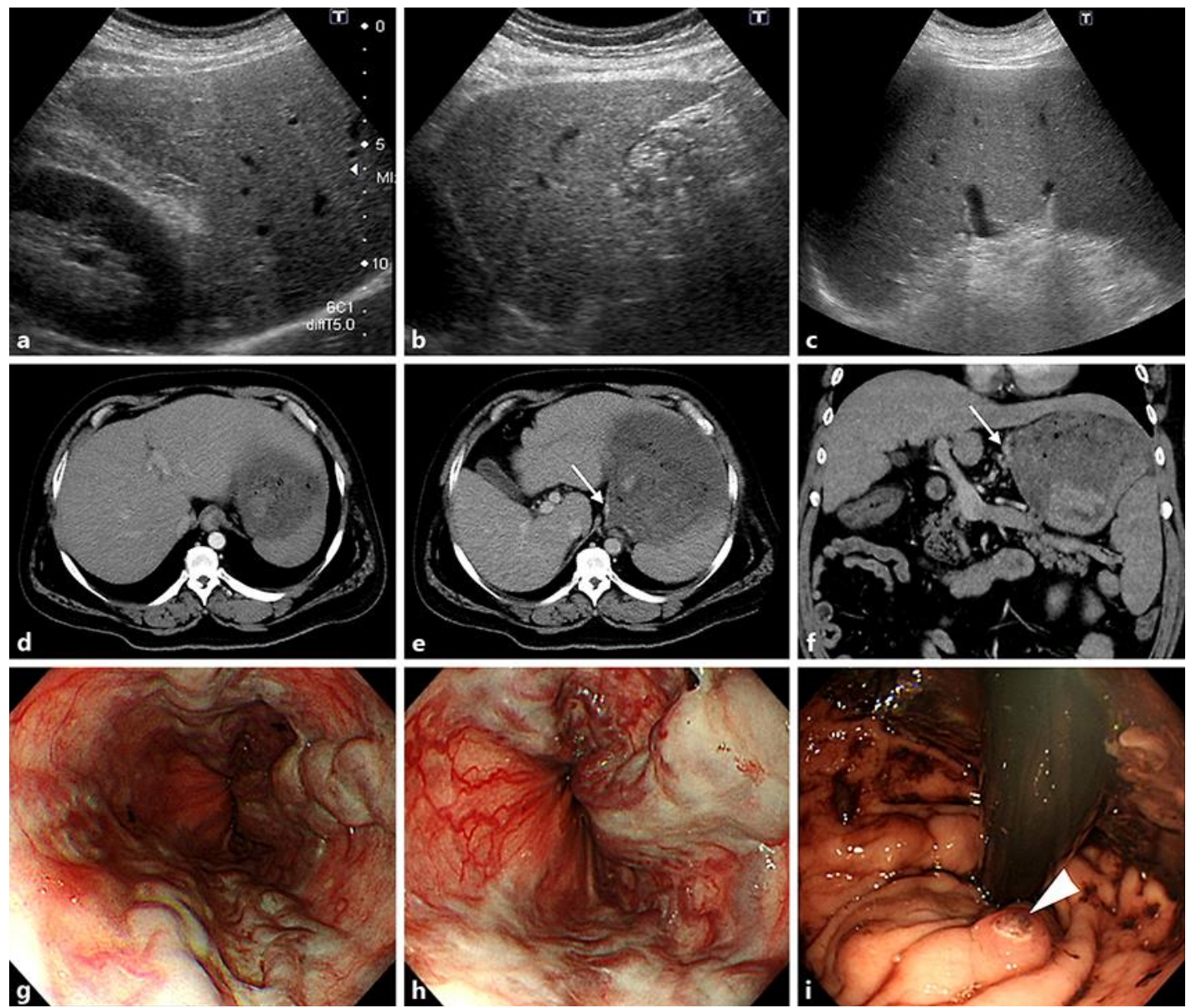

Fig. 1. Abdominal ultrasonography, contrast-enhanced CT and EGD images of the patient on admission. a-c Ultrasonography showing brightness, mild hepatorenal echo contrast, surface irregularity, and dullness of the edge of the liver and splenomegaly. $\mathbf{d}$ Contrast-enhanced CT showing an enlargement of the left hepatic lobe and splenomegaly. e, $\mathbf{f}$ Active contrast material extravasation iss also seen (arrow). g-i Endoscopic examination showing the esophageal varices (Lm, F3, Cb, and RC3) and gastric varices (LgC, RC1). i White plug exists on the gastric varices, but active bleeding cannot be observed (arrowhead). 


\section{Case Reports in Gastroenterology}

Case Rep Gastroenterol 2018;12:487-496
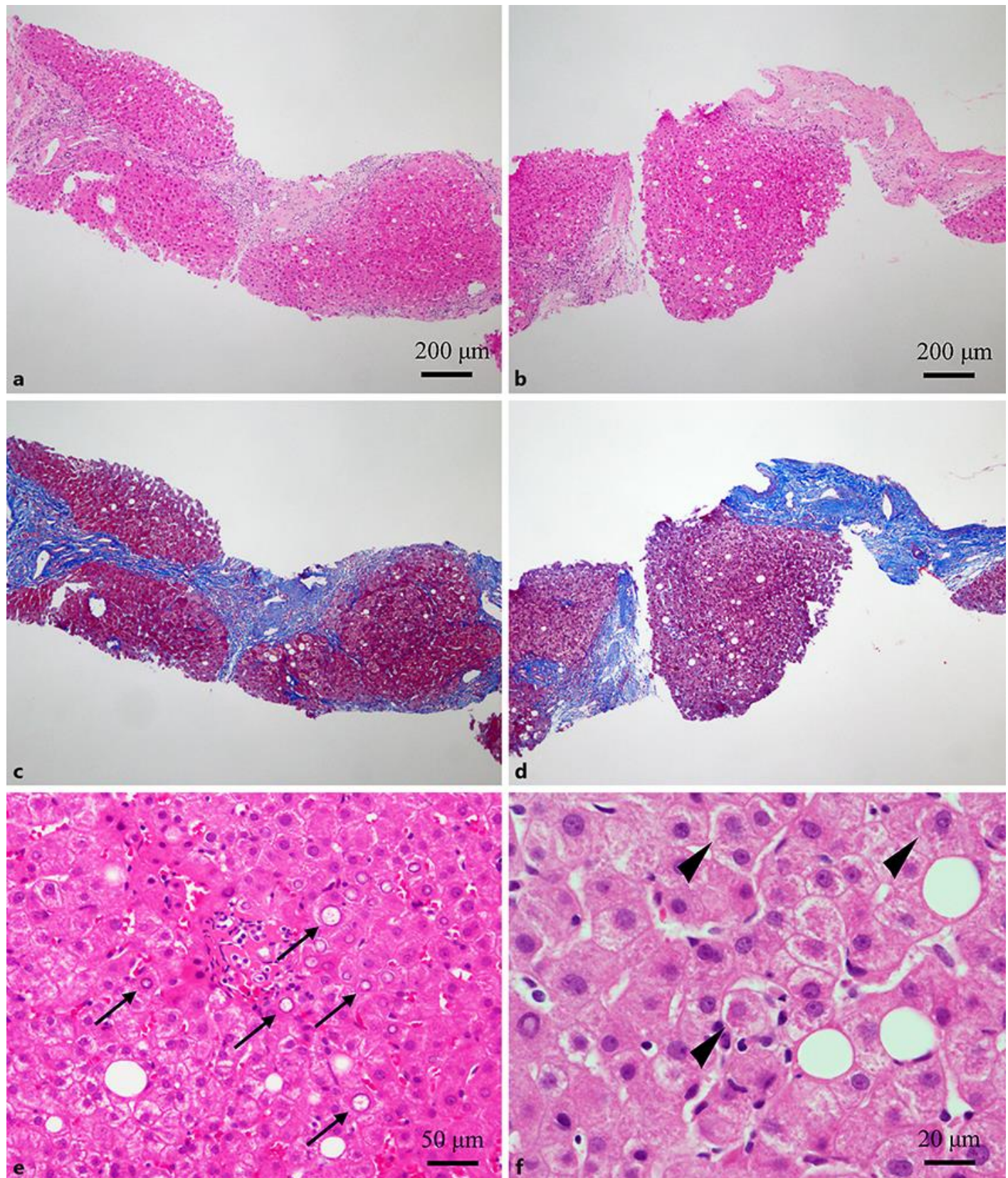

Fig. 2. Histopathological findings of the liver biopsy. a, b Hematoxylin and eosin staining $(\times 40)$ showing mild steatosis, ballooning, and lobular inflammation with spotty or focal necrosis. c, $\mathbf{d}$ Masson's trichrome staining $(\times 40)$ demonstrating severe fibrosis in the expanded portal areas with bridging fibrosis. e, $f$ Vacuolation of nucleus ( $\times 200$, arrows) and MDBs $(\times 400$, allowheads) can also be seen. 


\section{Case Reports in Gastroenterology}

Case Rep Gastroenterol 2018;12:487-496

(c) 2018 The Author(s). Published by S. Karger AG, Basel www.karger.com/crg

Honma et al.: A Young Adult Patient with Nonalcoholic Steatohepatitis Developed

Severe Gastroesophageal Varices Associated with Severe Obesity and Diabetes Mellitus
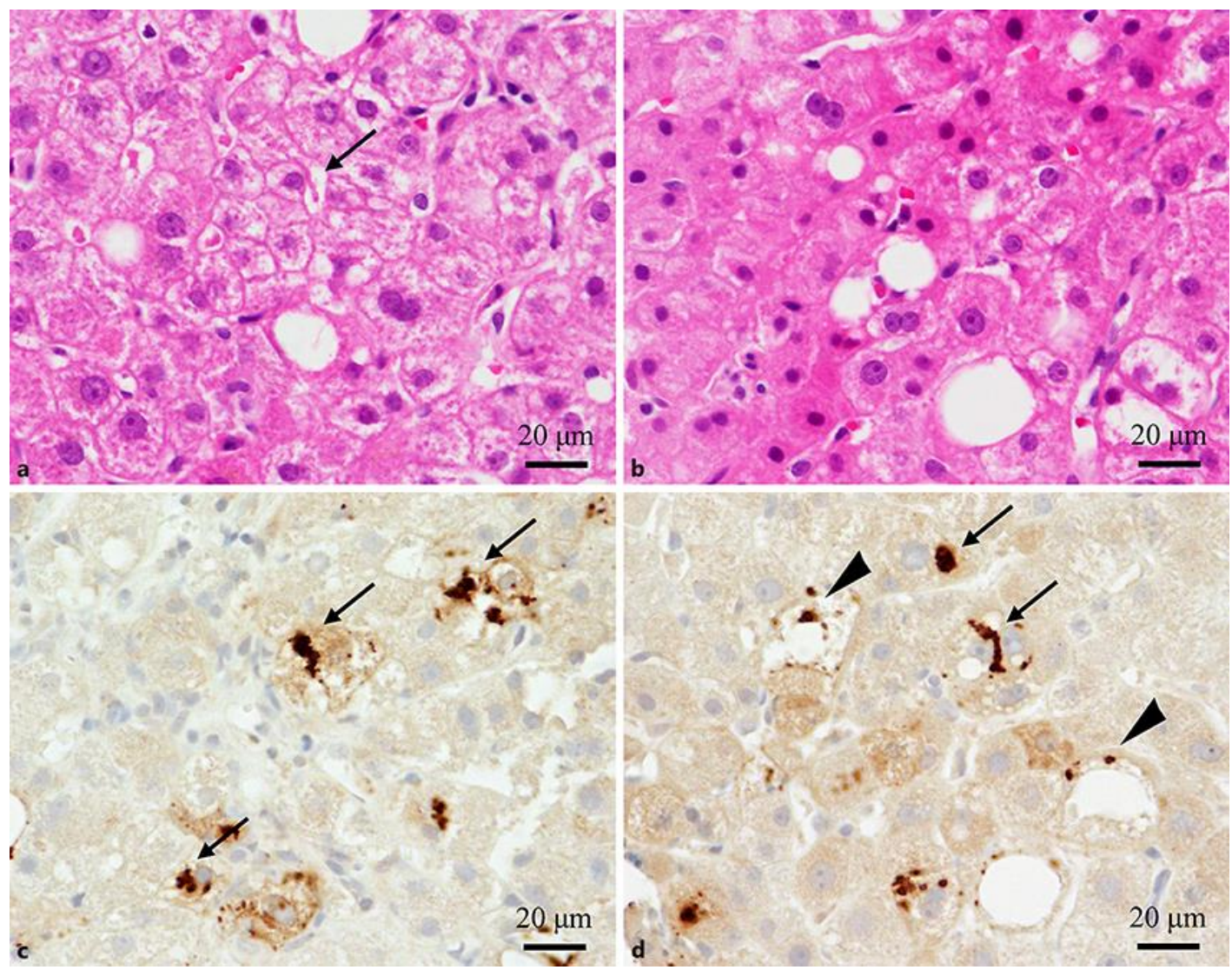

Fig. 3. Immunohistochemical analyses of MDBs. Compared with hematoxylin and eosin staining (a, b), immunostaining of p62 (c, d) detects MDBs (arrows) more clearly, especially when MDBs are very small and/or lipid droplets are present in hepatocytes (arrowheads). 
Gastroenterology

Honma et al.: A Young Adult Patient with Nonalcoholic Steatohepatitis Developed

Severe Gastroesophageal Varices Associated with Severe Obesity and Diabetes Mellitus

Table 1. Laboratory data on admission of the patient

\begin{tabular}{|c|c|c|c|c|c|c|c|c|}
\hline Hematology & & & $\mathrm{Na}$ & 136 & $\mathrm{mEq} / \mathrm{L}$ & Coagulation & & \\
\hline WBC & 15,100 & $/ \mu \mathrm{L}$ & $\mathrm{K}$ & 4 & $\mathrm{mEq} / \mathrm{L}$ & PT & 53.6 & $\%$ \\
\hline $\mathrm{RBC}$ & $280 \times 10^{4}$ & $/ \mu \mathrm{L}$ & $\mathrm{Cl}$ & 104 & $\mathrm{mEq} / \mathrm{L}$ & APTT & 43.4 & $s$ \\
\hline $\mathrm{Hb}$ & 7 & $\mathrm{~g} / \mathrm{dL}$ & $\mathrm{Fe}$ & 34 & $\mu \mathrm{g} / \mathrm{dL}$ & Fibrinogen & 162 & $\mathrm{mg} / \mathrm{dL}$ \\
\hline Hct & 22.4 & $\%$ & Ferritin & 49 & $\mathrm{ng} / \mathrm{mL}$ & D-dimer & 0.6 & $\mu \mathrm{g} / \mathrm{mL}$ \\
\hline PLT & $18.3 \times 10^{4}$ & $/ \mu \mathrm{L}$ & Hyaluronic acid & 187 & $\mathrm{ng} / \mathrm{dL}$ & FDP & 1.8 & $\mu \mathrm{g} / \mathrm{mL}$ \\
\hline Biochemistry & & & Ceruloplasmin & 24 & $\mathrm{mg} / \mathrm{dL}$ & Tumor markers & & \\
\hline $\mathrm{TP}$ & 5.3 & $\mathrm{~g} / \mathrm{dL}$ & Type IV collagen & 248 & $\mathrm{ng} / \mathrm{mL}$ & $\mathrm{AFP}$ & 5.6 & $\mathrm{ng} / \mathrm{mL}$ \\
\hline Alb & 2.9 & $\mathrm{~g} / \mathrm{dL}$ & M2BP & 2.71 & COI & PIVKA-II & 23 & $\mathrm{mAU} / \mathrm{mL}$ \\
\hline T-Bil & 0.8 & $\mathrm{mg} / \mathrm{dL}$ & PG & 298 & $\mathrm{mg} / \mathrm{dL}$ & Virus markers & & \\
\hline D-Bil & 0.4 & $\mathrm{mg} / \mathrm{dL}$ & $\mathrm{HbA} 1 \mathrm{c}$ & 8.1 & $\%$ & HBs Ag & $(-)$ & \\
\hline AST & 19 & IU/L & Glycoalbumin & 16.7 & $\%$ & HBc-IgG & $(-)$ & \\
\hline ALT & 18 & $\mathrm{IU} / \mathrm{L}$ & IRI & 14.5 & $\mu \mathrm{U} / \mathrm{mL}$ & $\mathrm{HCV} \mathrm{Ab}$ & $(-)$ & \\
\hline LDH & 208 & IU/L & Serology & & & Urine & & \\
\hline ALP & 135 & IU/L & CRP & 1.33 & $\mathrm{mg} / \mathrm{dL}$ & Protein & $( \pm)$ & \\
\hline$\gamma$-GTP & 65 & IU/L & ANA & 160 & $x$ & Blood & $(-)$ & \\
\hline $\mathrm{TG}$ & 181 & $\mathrm{mg} / \mathrm{dL}$ & Speckled type & & & Glucose & $(4+)$ & \\
\hline T-Cho & 76 & $\mathrm{mg} / \mathrm{dL}$ & AMA(M2) & 3 & & Keton body & $(-)$ & \\
\hline HDL-Cho & 17 & $\mathrm{mg} / \mathrm{dL}$ & IgG & 1,068 & $\mathrm{mg} / \mathrm{dL}$ & C-peptide & 192.2 & $\mu \mathrm{g} / \mathrm{day}$ \\
\hline LDL-Cho & 27 & $\mathrm{mg} / \mathrm{dL}$ & $\operatorname{Ig} A$ & 196 & $\mathrm{mg} / \mathrm{dL}$ & & & \\
\hline BUN & 25 & $\mathrm{mg} / \mathrm{dL}$ & $\operatorname{IgM}$ & 133 & $\mathrm{mg} / \mathrm{dL}$ & & & \\
\hline Cre & 0.64 & $\mathrm{mg} / \mathrm{dL}$ & Anti-GAD Ab & $<5.0$ & $\mathrm{U} / \mathrm{mL}$ & & & \\
\hline
\end{tabular}

